\title{
Atom Probe Tomography of Radiation-Induced Precipitation in Ferritic- Martensitic Alloy HCM12A
}

\author{
Z. Jiao, ${ }^{*}$ J. Penisten, ${ }^{*}$ G. S. Was, ${ }^{*}$ and R. L. Martens** \\ * Department of Nuclear Engineering and Radiological Sciences, University of Michigan, Ann \\ Arbor, MI 48109 \\ ** Central Analytical Facility, University of Alabama, Tuscaloosa, AL 35487
}

Ferritic-martensitic alloy HCM12A is considered for use in cladding and structural materials for advanced reactor systems. During reactor operation, structural components and cladding experience the displacement of atoms by collisions with neutrons, leading to microstructural changes and phase instability. Understanding these changes and developing mitigation strategies are the keys to establishing extended life components critical to economical reactor operation.

In this study, HCM12A samples were irradiated to $7 \mathrm{dpa}$ at $400^{\circ} \mathrm{C}$ using $2 \mathrm{MeV}$ protons in a Tandetron accelerator at the Michigan Ion Beam Laboratory. The damage profile calculated using the SRIM 2006 code [1] is shown in Fig. 1. Atom probe tomography (APT) tips from the protonirradiated region were made using the focused ion beam (FIB) lift-out method [2]. The tips were then analyzed using the local electrode atom probe (LEAP) system at the Central Analytical Facility at the University of Alabama. Fig. 2 shows the reconstruction of an APT tip containing a grain boundary. Precipitation was found to occur in the matrix, along dislocation loops and in the grain boundaries. The structure of the precipitates was found to have a $\mathrm{Cu}$-rich part neighboring a $\mathrm{Ni}$-, $\mathrm{Si}$ and $\mathrm{Mn}$ - part. The average size of the precipitates was $3.5 \mathrm{~nm}$ and the density was $1.6 \times 10^{23} \mathrm{~m}^{-3}$.

$\mathrm{Cu}$-rich precipitation has been reported in neutron irradiated reactor pressure vessel (RPV) steels with $\mathrm{Cu}$ concentration of $0.06 \mathrm{wt} \%$ and higher [3]. It may play an important role in the embrittlement of the RPV steels. The radiation-induced $\mathrm{Cu}$ - and Ni-rich precipitates in alloy HCM12A may cause potential embrittlement problems as found in RPV steels if used as a high temperature cladding or structural material. [4]

\section{References}

[1] J.F. Ziegler, J.P. Biersack and U. Littmark, The Stopping and Range of Ions in Solids, Pergamon, New York (1985).

[2] K. Thompson, D. Lawrence, D.J. Larson, J.D. Olson, T.F. Kelly and B. Gorman, Ultramicroscopy 107 (2007) 131-139.

[3] R. Chaouadi and R. Gerard, J. Nucl. Mater. 345 (2005) 65.

[4] This research was supported by the Department of Energy under contract \# DE-FG0707ID14894. 


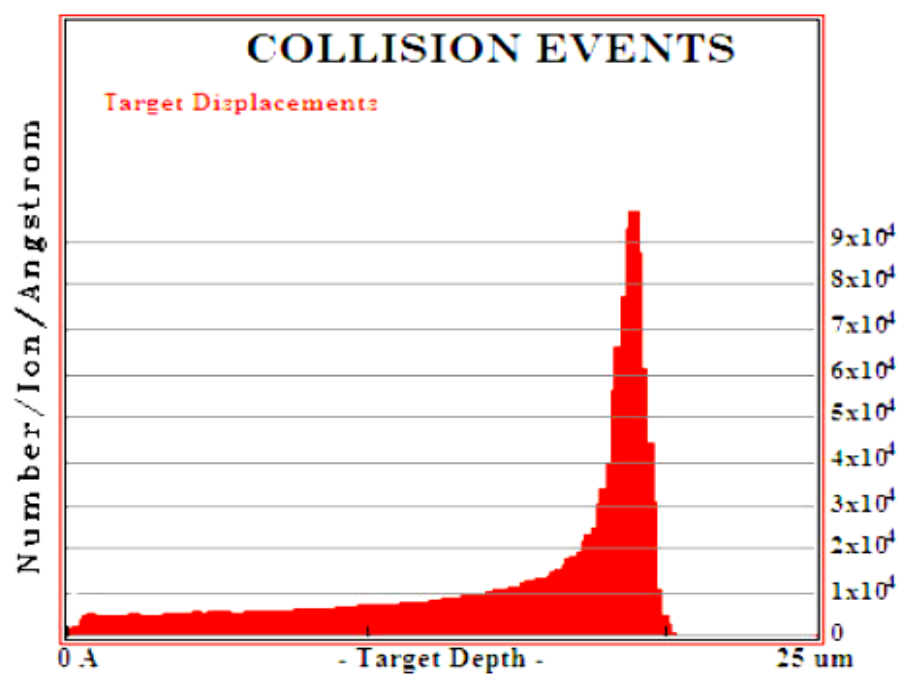

FIG. 1. TRIM calculation of the damage profile in HCM12A using $2 \mathrm{MeV}$ protons.

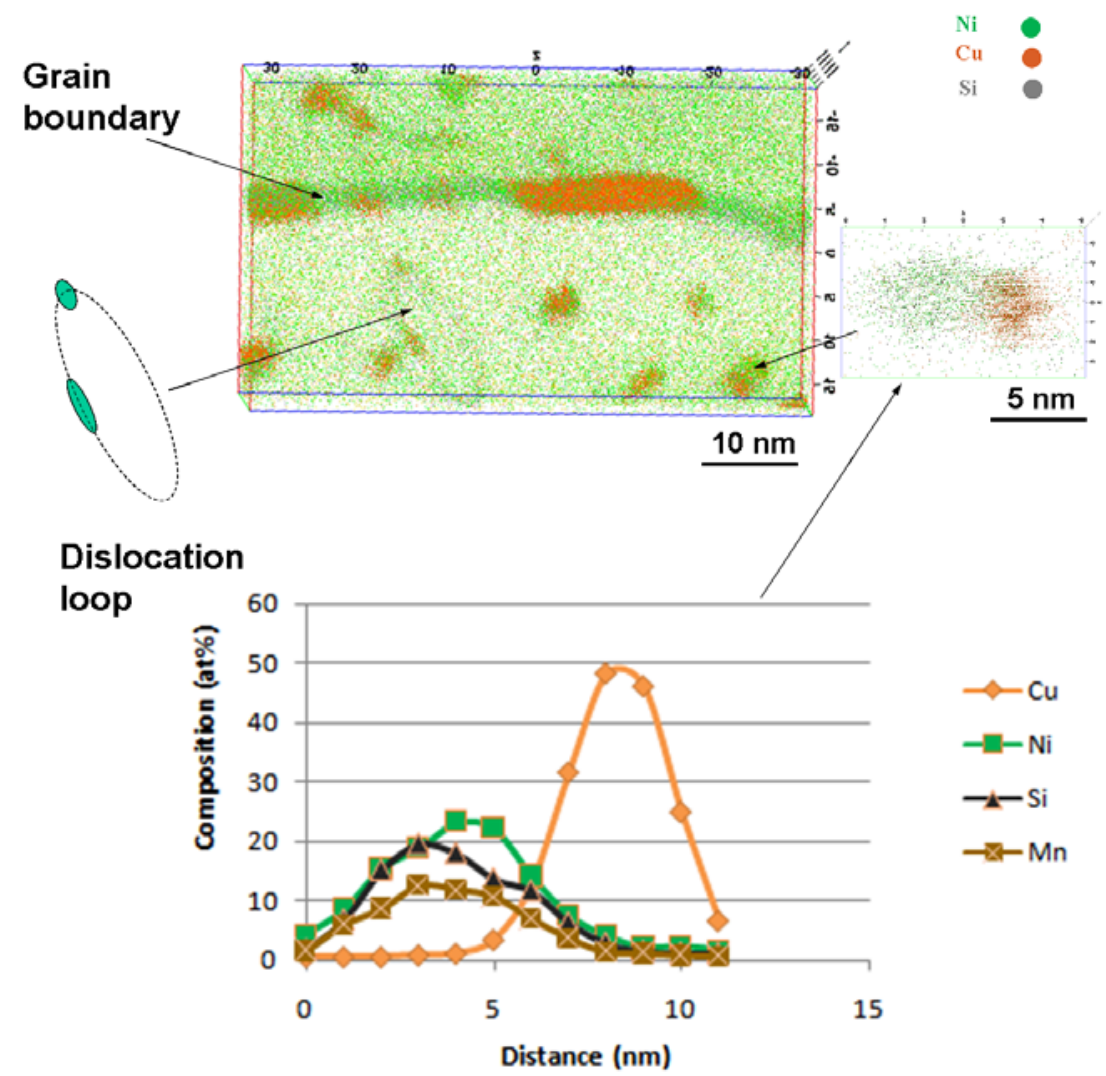

FIG. 2. APT showing precipitation in the matrix, on the dislocation loops and in the grain boundary. The right inset shows a blow-up image of a precipitate and the bottom plot shows the composition profile crossing the precipitate. 